\title{
Anabases
}

ANABASES Traditions et réceptions de l'Antiquité

22 | 2015

Varia

\section{J.-P. DRÈGE et M. ZINK (éd.), Paul Pelliot : de l'histoire à la légende}

\section{Annick Fenet}

\section{OpenEdition}

Journals

Édition électronique

URL : http://journals.openedition.org/anabases/5516

DOI : 10.4000/anabases. 5516

ISSN : 2256-9421

\section{Éditeur}

E.R.A.S.M.E.

\section{Édition imprimée}

Date de publication : 20 octobre 2015

Pagination : 274-275

ISSN : 1774-4296

\section{Référence électronique}

Annick Fenet, « J.-P. Drège et M. Zınk (éd.), Paul Pelliot : de l'histoire à la légende », Anabases [En ligne], 22 | 2015, mis en ligne le 20 octobre 2015, consulté le 22 septembre 2020. URL : http:// journals.openedition.org/anabases/5516 ; DOI : https://doi.org/10.4000/anabases.5516

Ce document a été généré automatiquement le 22 septembre 2020.

(c) Anabases 


\title{
J.-P. DrÈGE et M. ZINK (éd.), Paul Pelliot : de l'histoire à la légende
}

\author{
Annick Fenet
}

\section{RÉFÉRENCE}

J.-P. DRÈGE et M. ZINK (éd.), Paul Pelliot : de l'histoire à la légende. Colloque international organisé par Jean-Pierre Drège, Georges-Jean Pinault, Christina Scherrer-Schaub et Pierre-Étienne Will au Collège de France et à l'Académie des Inscriptions et BellesLettres (Palais de l'Institut), 2-3 octobre 2008, Paris, Académie des Inscriptions et Belles-Lettres, 2013, $598 \mathrm{p}$. 45 euros / ISBN 978-2-87754-290-6.

1 Cet ouvrage rassemble les contributions d'un gros colloque, organisé par plus de six institutions, tenu à l'occasion du centenaire de la visite du savant et explorateur français Paul Pelliot à Dunhuang en 1908, d'où il rapporta les fameux manuscrits datés des $\mathrm{VI}^{\mathrm{e}}-\mathrm{X}^{\mathrm{e}}$ siècles. La parution tardive de ces actes, aboutie grâce à la ténacité du sinologue Jean-Pierre Drège - ancien directeur de l'EfEo qui, ayant déjà œuvré au Centenaire de l'École en 2000, témoigne encore ici de son intérêt pour l'histoire de l'orientalisme -, explique que la bibliographie de la quasi-totalité des articles s'arrête en 2008 . Le résultat en vaut la peine, puisque le volume ne réunit pas moins de vingttrois études et deux avant-propos, tous (à l'exception de deux textes) en français : il convient à cet égard de saluer l'attachement de l'Académie à publier dans la langue de Molière.

2 La diversité des vingt-sept intervenants répond à la pluralité des domaines auxquels Paul Pelliot (1878-1945) a brillamment contribué par ses travaux : chinois bien sûr, mais aussi centro-asiatiques (p.335-370), extrême-orientaux (p.29-44), turcs (p. 419-432), mongols (p. 433-450), tibétains (p. 371-408), iraniens (p. 409-418), bouddhiques (p. 451-470)... sans oublier le christianisme oriental (éclairant article de M. Tardieu à ce sujet, p. 471-492), Marco Polo (p. 493-525) et l'histoire de l'art (p. 527-546). L'ensemble 
de l'ouvrage ne constitue donc pas une biographie : après une évocation générale du parcours de l'homme de science et d'action par J.-P. Drège (p. 3-7) et feu Jean Leclant (p.15-19), l'ouvrage aborde peu sa mission en Asie centrale (deux contributions, p. 45-120), mais s'attache surtout à étudier ses relations avec les institutions ou des collègues orientalistes (sept contributions, p. 21-28, 121-326) et surtout « l'apport de Pelliot aux études asiatiques" (quatorze contributions, p. 29-43 et 327-588). Le contexte historique et scientifique du savant et ses engagements divers - par exemple : à Pékin lors de la révolte des Boxeurs de 1900 (p.7, 17, 26); son obstination à maintenir, malgré l'interdiction de toute réunion publique, les séances de la Société asiatique dans le Paris occupé de la Seconde Guerre mondiale ; ou encore son mariage avec une Russe blanche (voir à ce propos les anecdotes pleines de saveur rapportées par o. de Bernon p. 209) - n'apparaissent que peu ou pas en filigrane, au travers des articles. C'est pourquoi l'on regrettera que le volume, illustré de quarante-trois figures dans le texte, ne soit malheureusement pas complété d'un index.

3 La grotte de Dunhuang fut donc visitée par le jeune savant durant son expédition en Asie centrale en 1906-1908. Le déroulement de cette mission est désormais bien connu par les écrits de l'intéressé, en particulier par ses Carnets de route de 1906-1908 (publiés en 2008 sous la coordination de J. Ghesquière). L'exploration archéologique de cette vaste contrée se développait alors dans un double processus d'émulation et de rivalités internationales, dans laquelle s'illustrait notamment Aurel Stein qui ramena aussi de la grotte de nombreux manuscrits pour le compte des Britanniques (articles de É. Trombert et de F. Wood, p. 45-82 et 121-136). Cependant, à l'inverse de ce dernier, le voyageur français noua des contacts avec ses collègues chinois, contacts qu'il entretint par la suite : c'est ce que révèle la très intéressante étude d'archives chinoises et de correspondances de savants chinois menée par R. Xinjiang et W. Nan (p. 83-119).

Pelliot entra également en relation avec ses homologues du Japon, où sa notoriété fut grande (p. 327-334), ainsi qu'avec des explorateurs et scientifiques russes avec lesquels il collabora durant près d'un quart de siècle (contribution de I. Popova, p. 313-326). L'édition de vingt-neuf lettres de son aîné Sylvain Lévi (1863-1935) et d'un discours inédit de Pelliot (par R.Lardinois, p. 212-270) éclaire une partie des réseaux institutionnels français dans lesquels évoluait le sinologue. C'est pourtant dans un tout autre contexte qu'il rencontra le tibétologue Jacques Bacot (1877-1965) : en Sibérie durant la Première Guerre mondiale (p. 203-212).

5 Son parcours réunit à lui seul toutes les institutions de son temps : diplômé de l'École des sciences politiques de Paris et de l'École des langues orientales, élève de l'EPHE, il est choisi comme membre de la toute jeune École française d'Extrême-Orient, officiellement créée en 1900 (p. 21-28). Élu au Collège de France à 34 ans, il a été mêlé à la création de l'Institut des Hautes Études chinoises entre 1919 et 1927 (p. 271-312). Le matériel ramené de son expédition a enrichi à la fois le musée Guimet (p. 547-552) et surtout la Bibliothèque nationale (longue contribution de N. Monnet, p.137-204, expliquant également « l'affaire » Farjenel). Mais ses acquisitions ne se limitèrent pas aux manuscrits de Dunhuang, elles consistèrent également en une gigantesque collection d'imprimés. Car Pelliot aimait les livres, à tel point qu'il fut aussi un bibliographe (p. 553-567).

6 Au fil des pages, le lecteur pénètre peu à peu la complexité de l'œuvre protéiforme de Pelliot, avant tout philologue, auteur de quelque 860 titres - défiant ainsi, bien avant l'heure, toute statistique bibliométrique. L'homme fait cependant défaut, laissant 
plutôt la place, comme l'indique le titre, à sa légende. Les lettres privées publiées dans les articles sont celles d'un Bacot, d'un Stein ou d'un Lévi ; la voix de Pelliot n'apparaît, mis à part les citations de ses Carnets, qu'au travers de correspondances institutionnelles ou d'extraits de ses articles ; seules certaines recensions polémiques laissent entrevoir un peu de sa personnalité (p.569-587). En refermant ce riche ouvrage, désormais indispensable pour appréhender une telle figure, l'on comprend l'admiration et les jalousies que le savant a pu susciter, ainsi que l'héritage formidable qu'il a laissé derrière lui et qui n'a pas fini d'être exploré.

\section{AUTEURS}

\section{ANNICK FENET}

UMR 8546 « AOROC »

annick.fenet@ens.fr 